\title{
DISSOLUTION KINETICS: THE NATURE OF THE PARTICLE ATTACK OF LAYERED SILICATES IN HF
}

\author{
W. E. KLINE† and H. S. FOGLER* \\ Department of Chemical Engineering. The University of Michigan, Ann Arbor, MI 48109, U.S.A.
}

(Received 7 April 1980; accepted 11 September 1980)

\begin{abstract}
The dissolution of layered silicates by hydrofluoric acid was studied with the aid of a slurry reactor. The nature of particle dissolution was delineated by measurements of reaction rates and by the examination of partially dissolved particles using a scanning electron microscope. The rates of particle dissolution per unit mass were modeled as a function of the fraction $x$ dissolved by an equation of the form $[-\bar{r}(x)] /[-\bar{r}(x=0)]=(1-x)^{n-1}$. For the three layer silicates the parameter $n$ takes on a value of $1 / 2$, reflecting radial attack at the unit cell edges. The reactive edge surface area is considerably smaller than the total wetted particle surface area. In contrast, the two layer kaolinite structure dissolves at both the layer edges and the planar faces, and the parameter $n$ varies from 0 to $t$ as the particle dissolution proceeds to completion. Comparison of the rates of dissolution on the basis of the actual reactive surface areas show that layered silicates having the same octahedral sheet dissolve at the same rate. It is concluded that attack is preferential at surfaces where the octahedral sheets are exposed.
\end{abstract}

\section{INTRODUCTION}

The heterogeneous nature of the layered silicates presents several problems in the analysis, comparison and interpretation of dissolution rate data. First, these structures are spatially heterogeneous. The exterior surfaces include both the planar faces and the edges of the two dimensional sheets comprising the unit layers. The unit layers of kaolinite and pyrophyllite, for example, are depicted by the Hofmann diagrams in Figs. 1 and 2 . It is evident that any study of the dissolution kinetics of the layered minerals must consider the likelihood of different rates of attack at each of these surfaces. It cannot be assumed that rate data based on the total particle surface area provides a true indication of the rates of the actual dissolution reactions.

Secondly, the layered lattices are chemically heterogeneous, consisting of separate and distinct silica, alumina and magnesia sheets. Consequently different rates of dissolution can be defined with respect to silicon, aluminum, magnesium, or any other chemical components present in the lattice. It is also possible that one or more of the constituent elements can be selectively lcached, or that attack at a particular sheet determines the rate at which the entire structure is dissolved.

In this investigation the dissolution of layered particles by hydrofluoric acid was studied by measurements of reaction rates and by the examination of partially dissolved particles with a scanning electron microscope. First, the stoichiometry of dissolution was studied in order to investigate the possibility of selective dissolution of particular lattice components. Next; the rela-

*Author to whom correspondence should be addressed.

†Present address: Exxon Production Research, Houston, Texas, U.S.A. tive importance of attack at the unit layer edges and faces of the three layer silicates was evaluated by rate experiments with montmorillonite clay and muscovite mica. Thirdly, the nature of the dissolution of kaolinite was investigated by a series of electron micrographs of partially dissolved particles. Subsequent rate experiments with additional partially dissolved kaolinite particles were then used to develop a model of particle attack. Finally, the results were used to compare the rates of dissolution of various silicates on a basis of the actual reacting surface area. This study represents the first reported analysis of the dissolution of layered silicates in hydrofluoric acid.

\section{PREVIOUS WORK}

Virtually all of the literature concerned with the acid attack of silicate surfaces describes leaching reactions in strong acids and the decomposition of clays where

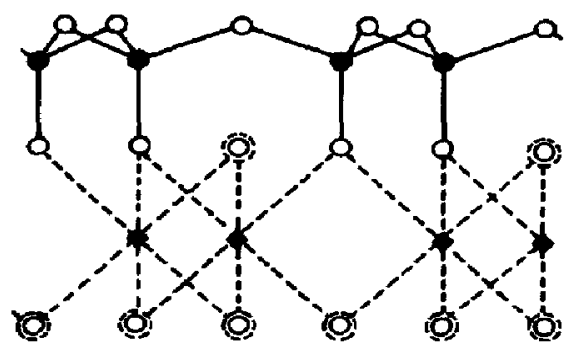

- Oxygen

(S) Hydroxyl

- Silicon

Aluminum

Fig. 1, Kaolinite unit cell. 


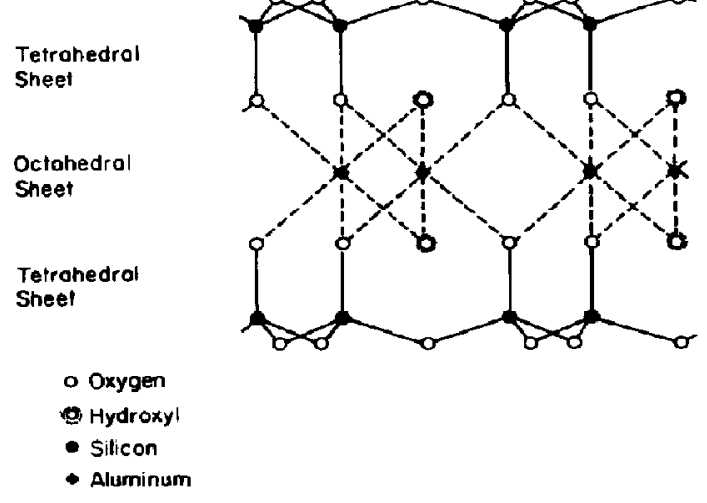

Fig. 2. Pyrophyllite unit cell.

exchangeable cations have been replaced by $\mathrm{H}^{+}$. The only investigation of the physical nature of particle dissolution in hydrofluoric acid was carried out by Blumberg $\{1,2]$ who found that the rate of disappearance of vitreous silica, $-r$, is related to the mass remaining at any time $t$ by the equation

$$
-r=k M^{2 / 3}
$$

where $k$ is a function of the acid concentration. Such a relationship describes a dissolution process in which attack is uniform over the entire exposed surface.

Studies of the dissolution of layered aluminosilicates in strong acids such as $\mathrm{HCl}$ give solid phase reaction orders ranging from zero to 1.55 . Controversy in this area was initiated by Osthaus $[3,4]$ who determined that the removal of aluminum from montmorillonites by hydrocloric acid may be represented by

$$
\ln \left(\frac{M}{M_{0}}\right)=k t
$$

where $M_{0}$ is the initial particle mass and $M$ is the mass remaining at time $t$. Subsequent experiments to evaluate the specific reaction rate parameter $k$ were reported by Miller [5], Packter [6], Turner [7] and Novak [8]. Each of these investigators concluded that the leaching of aluminum from montmorillonite takes place uniformly throughout the entire lattice, since eqn (1) constitutes the integrated form of a rate law which is first order with respect to the particle mass, i.e.

$$
-r=\frac{-\mathrm{d} M}{\mathrm{~d} t}=k M \text {. }
$$

It should be noted, however, that these rate laws were determined by an integral method of analysis in which the cumulative dissolution was measured as a function of time. A major disadvantage of this method is the insensitivity to changes in reaction rates during the course of dissolution, particularly as the dissolution nears completion. A much more sensitive test would have been the differential measurement of the initial dissolution rates of partially dissolved particles. In our work the development of a highly reproducible method for the measurement of initial rates allows the differential method of analysis to be applied to the dissolution of silicate particles by hydrofluoric acid.

In a contrasting interpretation, Eekman [9] suggested that the spontaneous alteration of hydrogen montmorillonite to aluminum montmorillonite proceeds with diffusion of adsorbed hydrogen ions from the edges along the particle radius. Eckman further extended these results to acid dissolution with the interpretation that attack takes place at the lattice edges. Similarly, Grandquist and Sumner[10] concluded that the changes in the measured BET surface areas of dried montmorillonite particles which had been partially dissolved in $\mathrm{HCl}$ were consistent with the changes predicted by a model postulating radial attack at the layer edges.

Studies of the attack of non-expandable layered structures by hydrochloric acid are likewise contradictory. Gastuche[11] showed that the hydrochloric acid attack of mica particles is accompanied by a rim of residual silica which advances radially inward as aluminum removal proceeds. Miller [5] reported that the dissolution of aluminum from kaolinite followed zero order kinetics with respect to the solid phase, and postulated a mechanism of diffusion controlled edge attack. In contrast, Turner [7] presented data which indicates that the leaching of aluminum from kaolinite by large excesses of $\mathrm{HCl}$ follows first order kinetics. Hulbert [12] proposed that the strong acid dissolution of calcined kaolinite is represented by a nucleation rate equation of the form

$$
\ln \left(\frac{M}{M_{\mathbf{0}}}\right)=k t^{m}
$$

where the exponent $m$ of time $t$ was found to vary from 1.1 to 1.55 .

It is obvious that previous results from studies of the strong acid dissolution of layered silicates give no indication as to the probable nature of hydrofluoric acid attack. Further studies were therefore undertaken to describe the dissolution in hydrofluoric acid as a function of the reactive surface area and the extent of reaction.

\section{EXPERIMENTAL}

The slurry reactor apparatus and technique used to measure dissolution rates have been described previously [13]. The reactor is a $150 \mathrm{~cm}^{3}$ IIastelloy vessel with agitation provided by a Teflon coated magnetic stirring bar (Fig. 3). The dissolving slurry is placed under nitrogen pressure, allowing samples to be withdrawn at short time intervals through submicron filters. Filtration of the mineral particles stops the dissolution reaction in the sample aliquols so that they are representative of dissolved mineral as a function of time. The progress of the reaction may then be monitored by analyzing the filtrate samples for dissolved lattice components by atomic absorption spectroscopy. For the small particles used in these experiments it can be shown that the limiting diffusional fluxes to the particle surface are orders of magnitude greater than the observed reaction 


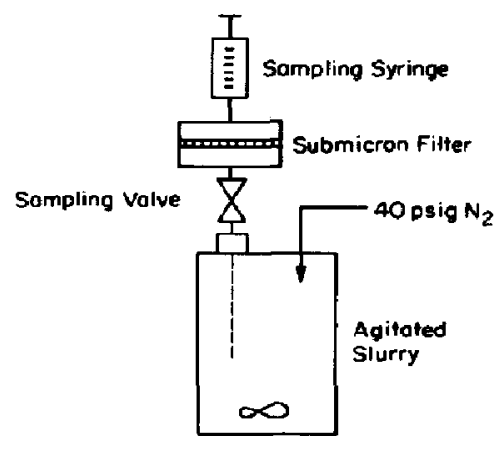

Fig. 3. Siurry reactor.

rates. The measured rates, therefore, are not controlled by mass transfer from the bulk solution to the solid surface.

The dry surface areas of the particles studied were measured by nitrogen BET. The wetted surface areas were measured by a nuclear magnetic resonance (NMR) technique. The basic concept of the NMR method is derived from the fact that the spin polarization relaxation time of a hydrogenous liquid in contact with a solid surface is different from the relaxation time of the bulk. Further details of the theory are given in Refs. [14]-[17]. All of the surface area measurements were provided through the courtesy of the Chevron Oil Field Research Company. Depending on the nature of the particles, the BET and NMR methods can give different results. Nitrogen molecules do not penetrate between the individual unit layers, so a nitrogen BET isotherm reflects only the external particle surface area. Water molecules, on the other hand, do penetrate between the layers of expandable clays such as sodium montmorillonite. As a result, the overall wetted montmorillonite surface area per unit mass can be more than an order of magnitude greater than the dry (BET) surface area.

The kaolinite particles were separated by air classification into size ranges of $0-1 \mu, 1-3 \mu, 3-5 \mu$ and $5+\mu$. The largest size fraction was employed in the electron microscope investigations. All of the electron micrographs were obtained using a JEOL JSM-U3 scanning electron microscope.

Partially dissolved montmorillonite and kaolinite particles were prepared by agitating a known mass of clay in hydrofluoric acid. This partial dissolution was followed by threc centrifuges and washes, drying at $100^{\circ} \mathrm{C}$ and weighing. The fraction dissolved was determined from the difference between the initial and final masses, and verified by atomic absorption analysis of the dissolved aluminum and silicon present in the solution phase.

\section{STOICHIOMETRY OF DISSOLUTION}

Without exception, all of the silicates studied in this work were dissolved in a stoichiometrically uniform manner by hydrofluoric acid. That is, the rate of removal of each of the elements within the lattice proceeded at a rate proportional to its lattice concentration. For example, the molar ratios of the dissolution rates with respect to silicon and aluminum were found to be $1: 1$ for kaol- inite (Fig. 1) and 2:1 for pyrophyllite (Fig. 2). This uniform dissolution is fundamentally different from the attack by strong acids, whereby aluminum is preferentially leached.

An important consequence of the fact that selective leaching does not take place when silicates are dissolved by hydrofluoric acid is that no residual product layer remains at the surface following dissolution. This is confirmed by electron micrographs of partially dissolved particles. The kinetics of reaction, therefore, are not controlled by a shrinking core mechanism in which attack at the solid surface is coupled with diffusion through a previously leached solid phase.

\section{COMPARISON OF DISSOLUTION AT UNIT LAYER FACES AND UNIT} LAYER EDGES

Evidence that attack at the unit layer cross sections of three layer lattices (Fig. 2) is significantly more important than reaction at the exposed faces was obtained from experiments which compared the dissolution rates of calcined and uncalcined sodium montmorillonite. Uncalcined sodium montmorillonite is an expandable clay. In an aqueous environment most of the interlayer faces are hydrated, resulting in significant swelling and very large wetted surface areas, as shown in Table 1 . When sodium montmorillonite is calcined at temperatures greater than $500^{\circ} \mathrm{C}$, however, the extent to which water molecules can penetrate between the unit layers is greatly reduced, and the calcined particles are characterized by much smaller wetted surface areas. Consequently the difference in dissolution rates between calcined and uncalcined montmorillonite particles is a direct indication of the importance of dissolution at unit layer faces, as opposed to dissolution at the unit layer edges or uniform attack throughout the lattice.

A comparison of the initial dissolution rates per unit mass of calcined and uncalcined sodium montmorillonite is shown in Fig. 4. No significant differences were observed, even when the wetted surface areas differed

Table 1. Particle surface areas measured by the NMR and BET methods

\begin{tabular}{|c|c|c|}
\hline Mineral & $\begin{array}{l}\text { Wetted (NMR) } \\
\text { Surface Area } \\
\left(\mathrm{m}^{2} / \mathrm{gm}\right) \\
\end{array}$ & $\begin{array}{l}\text { Dry (BET) } \\
\text { Surface Area } \\
\left(m^{2} / g m\right) \\
\end{array}$ \\
\hline Kaolinite & 16 & 15 \\
\hline Pyrophyllite & 22 & 32 \\
\hline Muscovite & 30 & 11 \\
\hline Illite & 79 & 31 \\
\hline $\begin{array}{l}\text { Sodium } \\
\text { Montmorillonite } \\
\text { (uncalcined) }\end{array}$ & 520 & 32 \\
\hline $\begin{array}{l}\text { Sodium } \\
\text { Montmorillonite } \\
\text { (calcined) }\end{array}$ & 68 & 16 \\
\hline Talc & 34 & 7 \\
\hline Phlogopite & 41 & 4 \\
\hline
\end{tabular}




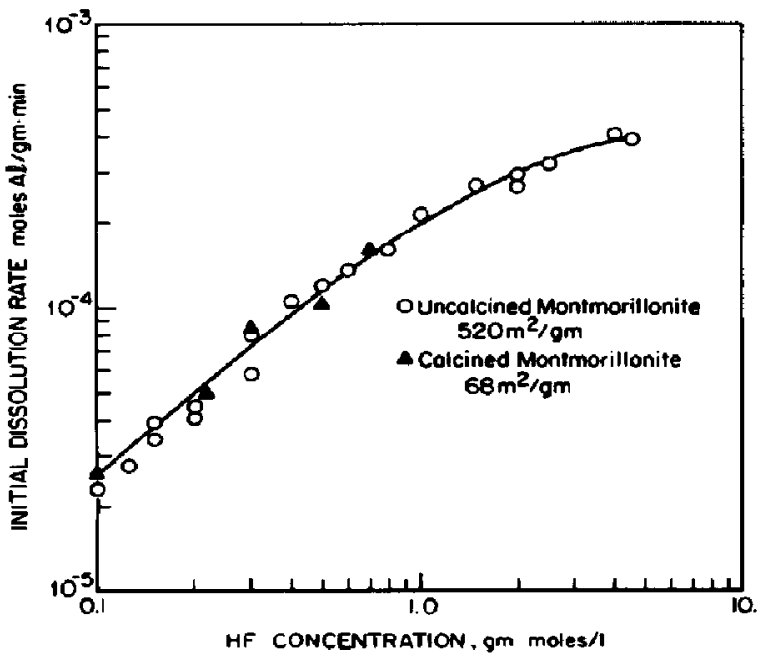

Fig. 4. Comparison of dissolution rates for calcined and uncalcined sodium montmorillonite.

by more than an order of magnitude. The conclusion is that the hydrofluoric acid attack of montmorillonite is not a function of the interlayer surface area.

One explanation of this independence with respect to the interlayer surface area is that the dissolution process consists of rapid diffusion of the acid into the lattice, uniform reaction throughout the layers, and finally, rapid diffusion of the reaction products back into the bulk. This possibility was tested by initial rate experiments with partially dissolved montmorillonite particles. If dissolution were to take place throughout the lattice, the mass dissolved per unit time would be proportional to the undissolved mass, $M$.

$$
-r=\frac{-\mathrm{d} M}{\mathrm{~d} t}=k M
$$

Consequently the rate of dissolution per unit particle mass,

$$
-\bar{r}=\frac{-\mathrm{d} M / \mathrm{d} t}{M}=k
$$

is not a function of the fraction $X$ dissolved. If dissolution takes place only at the surface, the rate of reaction per unit mass is proportional to the reactive surface area per unit mass, i.e.

$$
-\bar{r}=k^{\prime} A_{k}(X) / M(X)
$$

where $A_{R(x)}$ is the reactive particle surface area, which may or may not be the same as the total wetted surface area. After a fraction $X$ of the original particle mass has been dissolved, one can write

$$
\frac{M(X)}{M(X=0)}=(1-X)
$$

and

$$
\frac{A_{R}(X)}{A_{R}(X=0)}=(1-X)^{n}
$$

giving

$$
\frac{\bar{r}}{\bar{r}(X=0)}=(1-X)^{n-1}
$$

The exponent $\boldsymbol{n}$ is a function of the particle geometry and the physical nature of attack. Special cases are described in Table 2.

In Fig. 5 the initial rates of dissolution per unit mass of a sequence of partially dissolved montmorillonite particles are shown as a function of the fraction $X$ dissolved. It can be seen that the initial rates do show a dependence on the extent of dissolution, and the functionality can be described by using a value of $n=1 / 2$ in eqn (3). If the layered particles are described as disks, and assuming that the particle size distribution is fairly narrow, this result is consistent with the conclusion that the attack by hydrofluoric acid takes place predominantly at the unit layer edges.

It is important to note that even for non-expandable

\begin{tabular}{|c|c|}
\hline$n=0$ & $\begin{array}{l}\text { Reactive surface area per unit } \\
\text { moss remains constant as moss } \\
\text { decreoses (e.g., uniform attack } \\
\text { at a planar surfoce) }\end{array}$ \\
\hline$n=1 / 2$ & $\begin{array}{l}\text { Radial attock of a cylindrical } \\
\text { configuration }\end{array}$ \\
\hline$n=2 / 3$ & $\begin{array}{l}\text { Uniform attack of a partical } \\
\text { for which } A_{R} \propto M^{2 / 3}\end{array}$ \\
\hline$n=1$ & $\begin{array}{l}\text { Reoctive surface oreo per unit } \\
\text { mass remoins constont (e.g.. } \\
\text { perforation of a planar surfoce) }\end{array}$ \\
\hline
\end{tabular}
layered silicates such as kaolinite and muscovite, the bulk of the total wetted particle surface area still consists of exposed portions of the interlayer faces. The

Table 2. Special cases of the exponent $n$ as a function of the fraction of mass dissolved $X$

$$
\frac{r(x)}{r_{0}}=(1-x)^{n-1}
$$




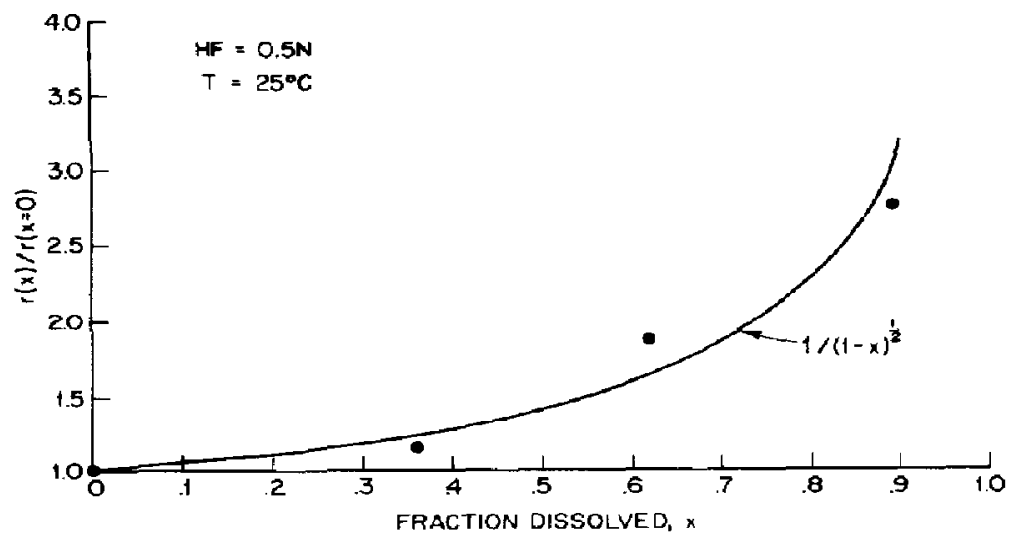

Fig. 5. Dissolution rates per unit mass for partially dissolved sodium montmorillonite.
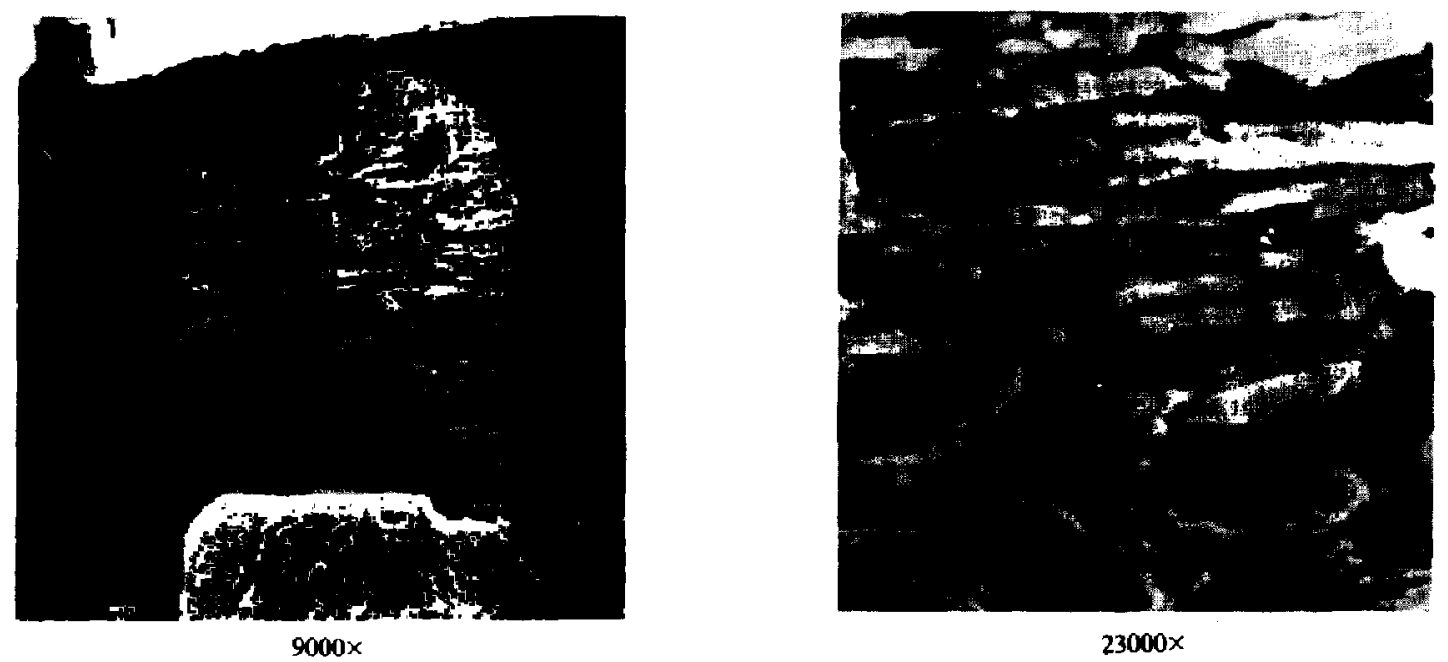

Top Face of Particle

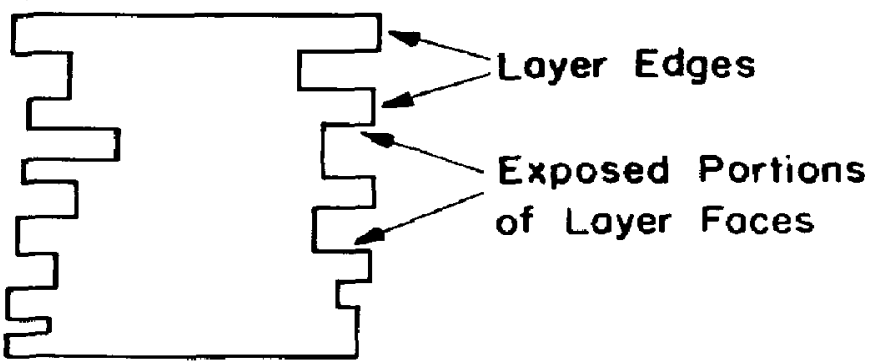

\section{Bottom Face of Porticle}

Fig. 6. Electron micrographs and schematic representation of the circumference of a kaolinite particle. 
electron micrographs in Fig. 6 show the circumferences of a kaolinite particle, $5 \mu \mathrm{m}$ in diameter. In addition to the exposed layer edges, a substantial amount of interlayer surface is accessible because of irregularities and uneven stacking of the layers. For a $5 \mu \mathrm{m}$ kaolinite particle, the wetted surface area of $16 \mathrm{~m}^{2} / \mathrm{g}$ constitutes $1 \%$ of the total theoretical interlayer area of $1070 \mathrm{~m}^{2} / \mathrm{g}$. This measured surface area per unit mass is much larger than the calculated superficial area per unit mass of the top and bottom faces,

$$
\bar{A}_{S F}=\frac{2}{\rho h}=0.15 \mathrm{~m}^{2} / \mathrm{g}
$$

or the superficial edge area around the particle circumference,

$$
\bar{A}_{S E}=\frac{4}{\rho D}=0.3 \mathrm{~m}^{2} / \mathrm{g}
$$

(assuming a diameter, $D$, of $5 \mu \mathrm{m}$, a particle height, $h$ of $5 \mu \mathrm{m}$, a density of $2.7 \mathrm{~g} / \mathrm{cm}^{3}$ and either a cylindrical or rectangular geometry). Likewise, for a muscovite particle $20 \mu \mathrm{m}$ in diameter, the wetted particle surface area per unit mass of $30 \mathrm{~m}^{2} / \mathrm{g}$ represents $4 \%$ of the theoretical interlayer area, while the calculated top and bottom face area per unit mass and the superficial edge area per unit mass are only $0.15 \mathrm{~m}^{2} / \mathrm{g}$ (assuming a particle thickness of $5 \mu \mathrm{m}$ ) and $0.07 \mathrm{~m}^{2} / \mathrm{g}$, respectively. Therefore, if the three layer silicates such as sodium montmorillonite and muscovite are not dissolved at the unit cell faces, it follows that the reactive surface areas are considerably smaller than the total wetted particle surface areas.

Further evidence that the HF attack at the three layer silicates is dominant at the layer edges can be obtained from measurements of the dissolution rates of muscovite mica. In contrast to the fine grained clays, micas occur naturally in extensive sheets. This fact makes possible experiments by which reaction rates at the edges and faces may be directly compared.

In a previous study, a rotating disk apparatus was used to measure the rates at which the layer faces of nuscovite are dissolved in hydrofluoric acid. Muscovite sheets were cut into disks having a face surface area of $20 \mathrm{~cm}^{2}$, and the edges were sealed with epoxy. The attack was extremely slow, and precise measurements of the rates of dissolution were not possible. From the data obtained, however, it can be calculated that the reaction rate at the layer faces in $20 \% \mathrm{HF}$ at $25^{\circ} \mathrm{C}$ is less than $10^{-13}$ moles mica dissolved per $\mathrm{cm}^{2}$ per second.

Rates of dissolution at unit layer edges can be obtained from track etching experiments which follow the radial enlargement of small holes within mica sheets, as described by Bean [18]. Thin sheets (less than $10 \mu \mathrm{m}$ ) are irradiated by fission products from a radioactive source such as Californium. This bombardment leaves tracks which grow radially when the exposed circumferences are attacked by hydrofluoric acid. The rate of pore growth is measured by monitoring the conductance across the sheets as dissolution proceeds. This pore growth may then be related to the rate of dissolution per unit surface area at the pore walls by eqn (4).

$$
\frac{-\mathrm{d} M / \mathrm{d} t}{\pi D h}\left(\frac{\mathrm{g}}{\mathrm{cm}^{2} \cdot \sec }\right)=\frac{1}{2} \rho \frac{\mathrm{d}(D)}{\mathrm{d} t}
$$

where $D$ is the pore diameter, $\rho$ is the mica density and $h$ is the axial dimcnsion of the pore. In experiments by Bean [18] and by Anderson[19] irradiated muscovite sheets $7 \mu \mathrm{m}$ thick were etched by $20 \%$ hydrofluoric acid at $25^{\circ} \mathrm{C}$. The measured pore diameter growth rate of $1.2 \AA / \mathrm{sec}$ corresponds to an edge dissolution rate of $2 \times 10^{-8} \mathrm{~g} / \mathrm{cm}^{2} \cdot \mathrm{sec}$, which is orders of magnitude greater than the rate of attack at the planar faces. Consequently the overall rate of dissolution for muscovite particles can be attributed entirely to reaction at the edges.

The reactive particle surface area can be obtained by dividing the rate per unit mass by the rate of dissolution per unit edge area. For muscovite particles having a mean diameter of $20 \mu \mathrm{m}$, a dissolution rate of $5 \times 10^{-5} \mathrm{~g}$ dissolved/g $\cdot \sec$ was measured in $20 \% \mathrm{HF}$ at $25^{\circ} \mathrm{C}$. Dividing by the edge dissolution rate of $2 \times$ $10^{-\mathrm{s}} \mathrm{g} / \mathrm{cm}^{2} \cdot \mathrm{sec}$ gives a reactive surface area of $0.25 \mathrm{~m}^{2} / \mathrm{g}$, which is two orders of magnitude smaller than the total wetted particle surface area of $30 \mathrm{~m}^{2} / \mathrm{g}$. This calculated reactive surface area, however, is quite comparable to the superficial edge area of $0.07 \mathrm{~m}^{2} / \mathrm{g}$. The actual edges, of course, are not smooth, and the factor of four by which the reactive surface area exceeds the superficial area can be attributed to "roughness" resulting from steps and other irregularities. The edge area of a disk having regular angular indentations of 29 degrees, for example, is greater than the superficial circumference area by a factor of 4 .

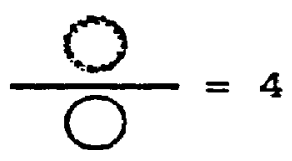

The conclusion is that the three layer lattices such as muscovite and montmorillonite are attacked almost exclusively at the exposed cross sections of the unit cell edges. The remainder of the surface, consisting of exposed portions of the unit cell faces, dissolves at a rate which can be considered as negligible.

An entirely different result was obtained for the dissolution of the two layer kaolinite clay particles. The kaolinite lattice differs from the three layer minerals in that the octahedral alumina sheet is exposed at both the layer faces and the edges (compare Fig. 1 with Fig. 2). Electron micrographs and kinetic experiments with partially dissolved particles indicate that kaolinite is attacked appreciably at each of these surfaces.

Electron micrographs of a $5 \mu \mathrm{m}$ kaolinite particle after $19 \%$ of the mass has been dissolved are shown in Fig. 7 . Compared to the undissolved particle in Fig. 6, the circumference has been smoothed, an indication of attack at the edges. In addition, a top view of the partially dissolved particle reveals an etched surface at which planar surfaces several layers deep are exposed, 

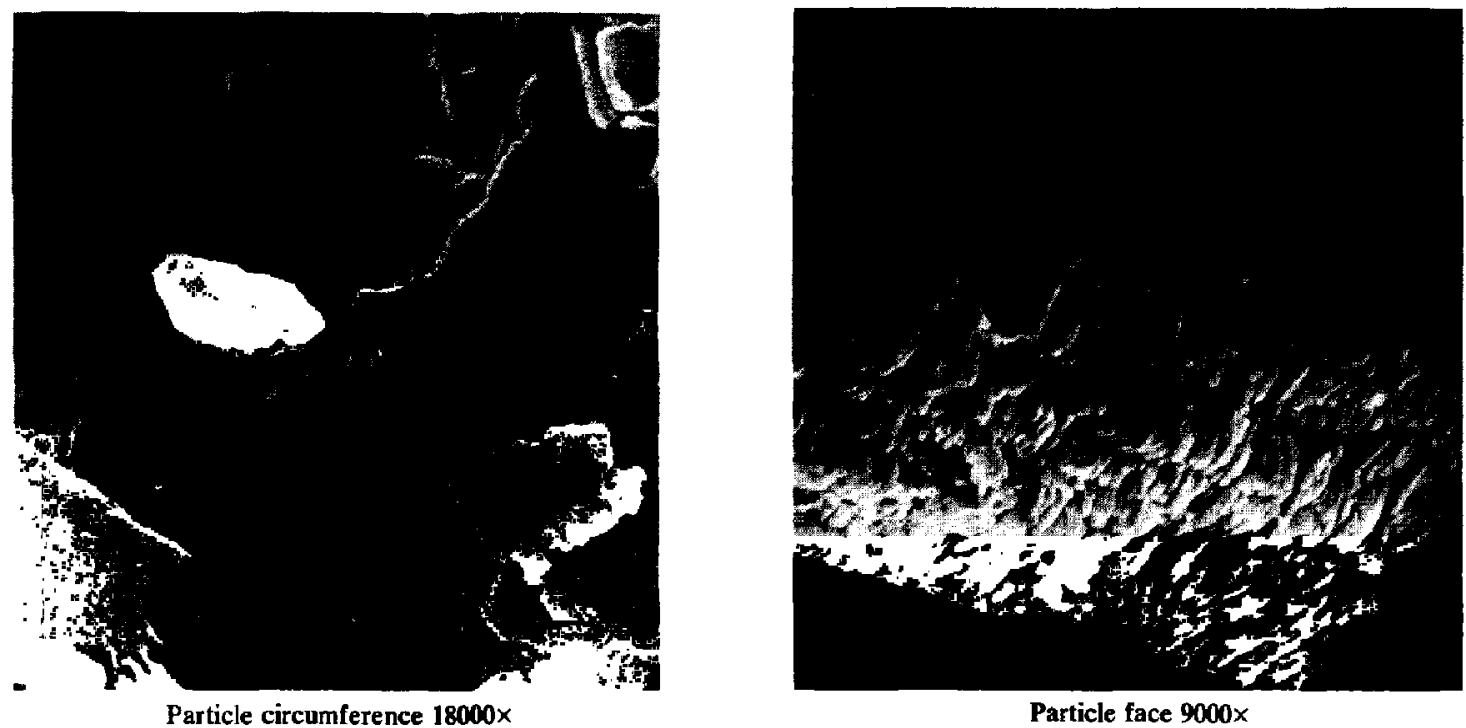

Particle face $9000 \times$

Fig. 7. Kaolinite particles dissolved $19 \%$.

suggesting that dissolution has taken place at the unit cell faces as well as at the edges.

At $36 \%$ dissolution (Fig. 8) the evidence of attack at the unit cell faces is even more pronounced. Crevices and holes are evident at the exposed faces, and these dissolved regions form a network extending over the entire planar surface. In addition, it can be seen that the layer stacks have begun to split, exposing additional interlayer area. When the fraction dissolved has reached 62\% (Fig. 9) the dissolution at the planar face is substantial. The layer stacks have been split into thin flakes, which have been perforated throughout the entire exposed surface. The flake shown in Fig. 9 is approximately $3 \mu \mathrm{m}$ in diameter. By the time $95 \%$ of the original kaolinite has been dissolved (Fig. 10) the undissolved portions of the perforated flakes have split into small fragments of less than $1 \mu \mathrm{m}$.

The important indication of the electron micrographs of Figs. 6-10 is that the reactive surface of the two layer

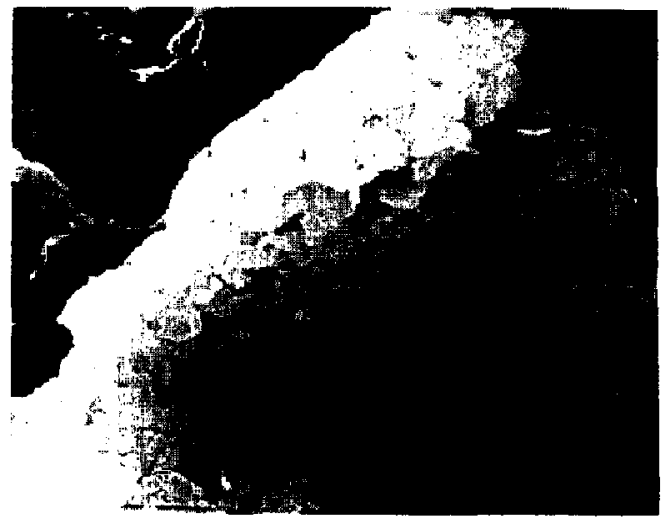

Particle face $12000 x$ kaolinite lattice includes both the particle edges and the exposed planar surfaces. In contrast, the three layer lattices are dissolved primarily at the unit cell edges. The considerable difference in the attack of hydrofluoric acid at the respective faces of two and three layer silicates can be further seen by comparing Fig. 11, which shows the effect of dissolving three layer muscovite particles by $40 \%$, with the partially dissolved kaolinite particles in Figs. 8 and 9. One notes that the partially dissolved muscovite particle does not exhibit the holes and crevices characterizing the faces of kaolinite particles dissolved to a comparable extent.

Measurements of the wetted surface areas per unit mass, $\bar{A}(X)$, (using the NMR technique) and the initial rates of dissolution per unit mass, $\bar{r}(X)$, were obtained for a sequence of kaolinite particles representing various stages of the dissolution process. Figure 12 shows the ratios $\bar{r}(X) / \bar{r}(X=0)$ and $\bar{A}(X) / \bar{A}(X=0)$ as a function of the dissolved fraction $X$. It can be seen that the initial

Fig. 8. Kaolinite particles dissolved $36 \%$.

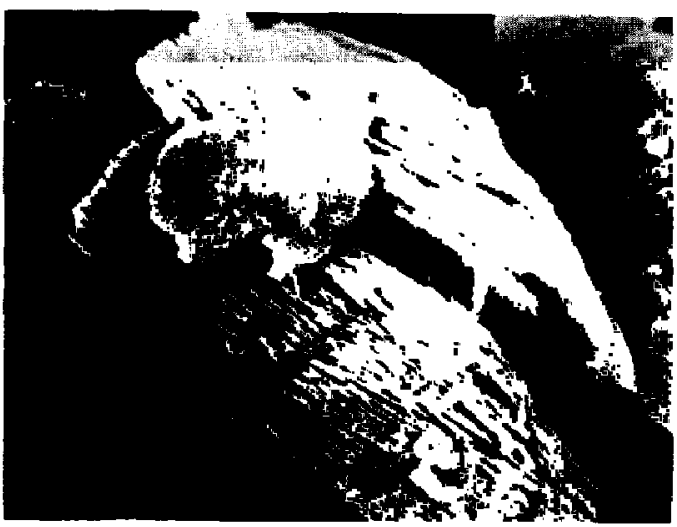

Particle edge $14000 \times$ 


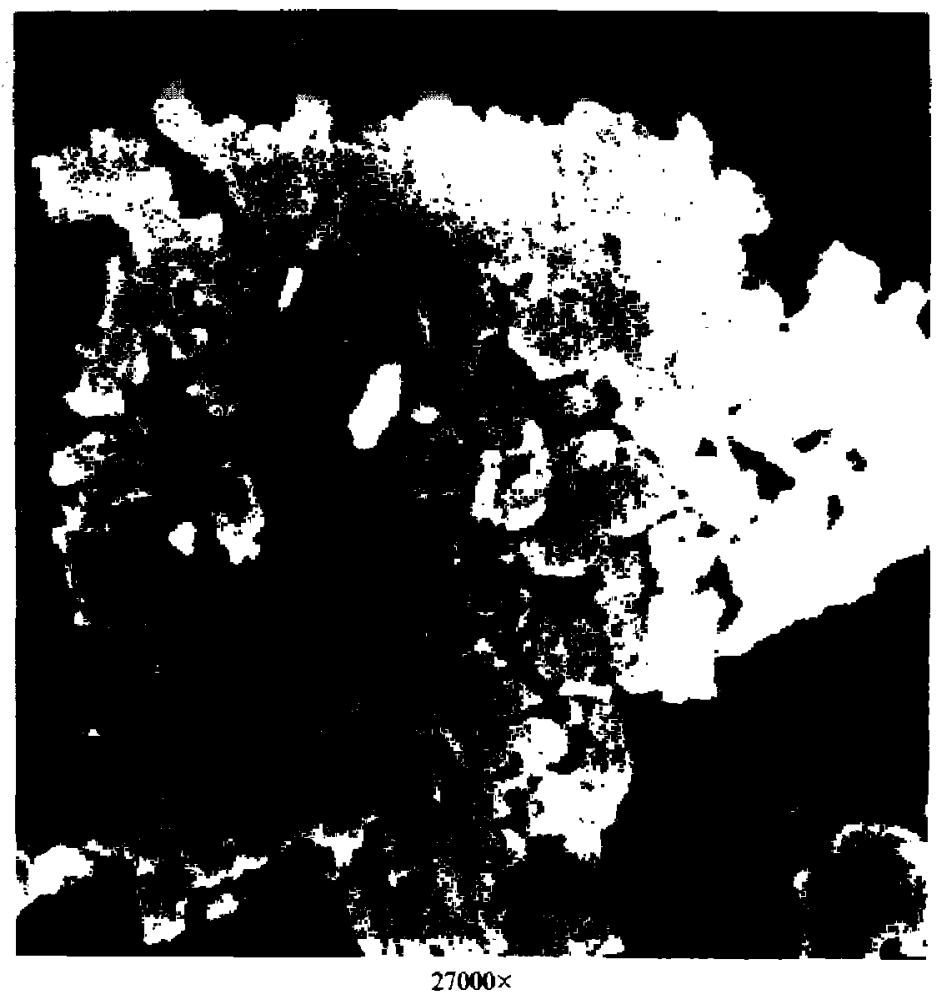

Fig. 9. Top view of kaolinite particle dissolved $62 \%$.

rates of dissolution per unit mass and the total wetted surface areas are identical functions of the extent of dissolution, thus confirming the conclusion that the rate at which hydrofluoric acid dissolves kaolinite is proportional to the entire wetted surface area.

As shown previously, the relationship between $-\bar{P}(X)$ and $X$ is described by an equation of the form

$$
\frac{\bar{r}(X)}{\bar{r}(X=0)}=(1-X)^{n-1}
$$

where the exponent $n$ can also be a function of $X$. In Fig. 5 it was shown that the dissolution of sodium montmorillonite is consistent with a model of radial edge attack, for which $n=1 / 2$ throughout the course of dissolution. In general, the exponent $n-1$ is given as a function of $X$ by the slope of a plot of $\ln (\bar{r}(X) / \bar{r}(X=0)$ vs In $(1-X)$. Figure 13 replots the kaolinite data from Fig. 12 in this manner. Note that the slope is essentially $-1(n=0)$ at the beginning of dissolution, indicating that the total surface area does not change as the particle mass decreases. During this initial stage of the dissolution process (shown schematically in Fig. 14) attack at the exposed layer faces simply uncovers equivalent portions of adjacent underlying layers, with little change in the total surface area. As the particles split into thin flakes, however, subsequent attack of successive underlying layers results in complete penetration of the flake and the formation of holes, thus exposing new edge surface area and eliminating some of the face surface exposed to the acid. Dissolution proceeding radially from sites throughout the layers becomes important, and the magnitude of the exponent $(n-1)$ is progressively reduced from -1 toward the value of $-1 / 2$ characteristic of edge attack. As the dissolution proceeds to completion, the flake thickness $h$ becomes very small, and the exposed face area per unit mass (proportional to $1 / h$ ) is again dominant. At this point the removal of mass from any face site results in the almost immediate formation of a hole. The resultant decrease in the planar surface area ( $\pi a^{2}$, where $a$ is the hole radius) is proportional to the mass removed $\left(\pi a^{2} h \rho\right)$. Where this rapid perforation of thin flakes comprises a significant fraction of the total dissolution process, therefore, the reactive surface area per unit mass approaches a constant value and the exponent $(n-1)$ approaches zero. Consequently, the overall process by which the dissolution of kaolinite proceeds from $X=0$ to $X=1$ can be described as a continuous transition from a constant surface area reaction $(n=0)$ to a reaction where the surface area per unit mass remains constant $(n=1)$.

\section{COMPARISON OF DISSOLUTION RATES}

One notes that each of the layered silicates studied is attacked primarily at those surfaces where the octahedral sheets, are exposed. The fact that the three layer silicates are dissolved at the layer edges, while kaolinite is attacked at both the edges and the planar faces, suggests that the overall rates of particle dissolution are determined by the reaction at the octahedral sheets. This 


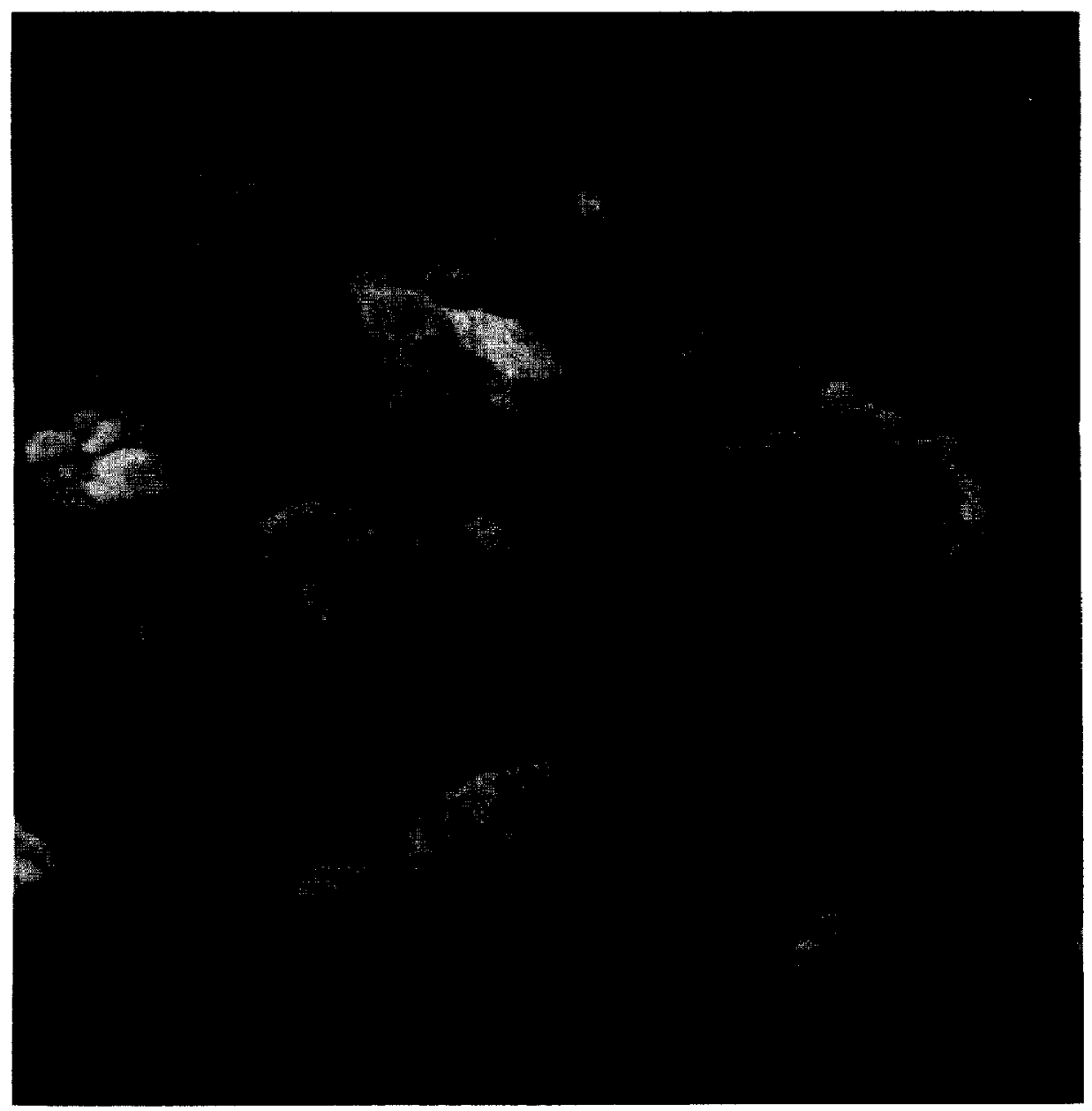

$24000 x$

Fig. 10. Top view of kaolinite particle dissolved $95 \%$.

conclusion can be tested by comparing the rates of dissolution of various aluminum and magnesium silicates. One would expect that different layered silicates with the same octahedral sheet should be dissolved by hydrofluoric acid at similar rates. However, before any meaningful comparisons can be made with regard to structure, it is necessary to reduce the dissolution rates to a common basis of reactive surface area. For example, dissolution rates for sodium montmorillonite expressed on the basis of the entire wetted surface area of more than $500 \mathrm{~m}^{2} / \mathrm{g}$ are relatively meaningless, since it has been shown that most of that area does not contribute appreciably to the overall dissolution. Similarly, rate data reported on a unit mass basis depends on particle size and the relative fractions of the edge and face areas. An important result of this work, therefore, is that the identification of those portions of the layered silicates where attack is predominant makes it possible to express the rates of silicate dissolution on the basis of reactive surface area.

Dissolution rates were measured as a function of the concentration of hydrofluoric acid and temperature for the aluminosilicates kaolinite, sodium montmorillonite, illite, pyrophyllite and muscovite, and for the magnesium silicates talc and phlogopite. The corresponding structural characteristics are described schematically in Table 3. The specific rate constants $k$

$$
-r_{0}=k f(\mathrm{HF})
$$

obtained from this data are given in Table 4 in terms of both reactive surface areas and overall wetted particle surface areas. Since the relative proportions of silicon, aluminum and magnesium are different in each of these minerals, the rate constants are reported in units of moles of mineral dissolved per $\mathrm{cm}^{2}$ per sec per (HF molarity). The reactive surface areas of the three layer particles were calculated assuming that dissolution takes place exclusively at the layer edges, and that the reactive surface area is greater than the superficial edge area by the "roughness" factor of

$$
\frac{0.25 \mathrm{~m}^{2} / \mathrm{g}}{0.07 \mathrm{~m}^{2} / \mathrm{g}} \doteq 4
$$




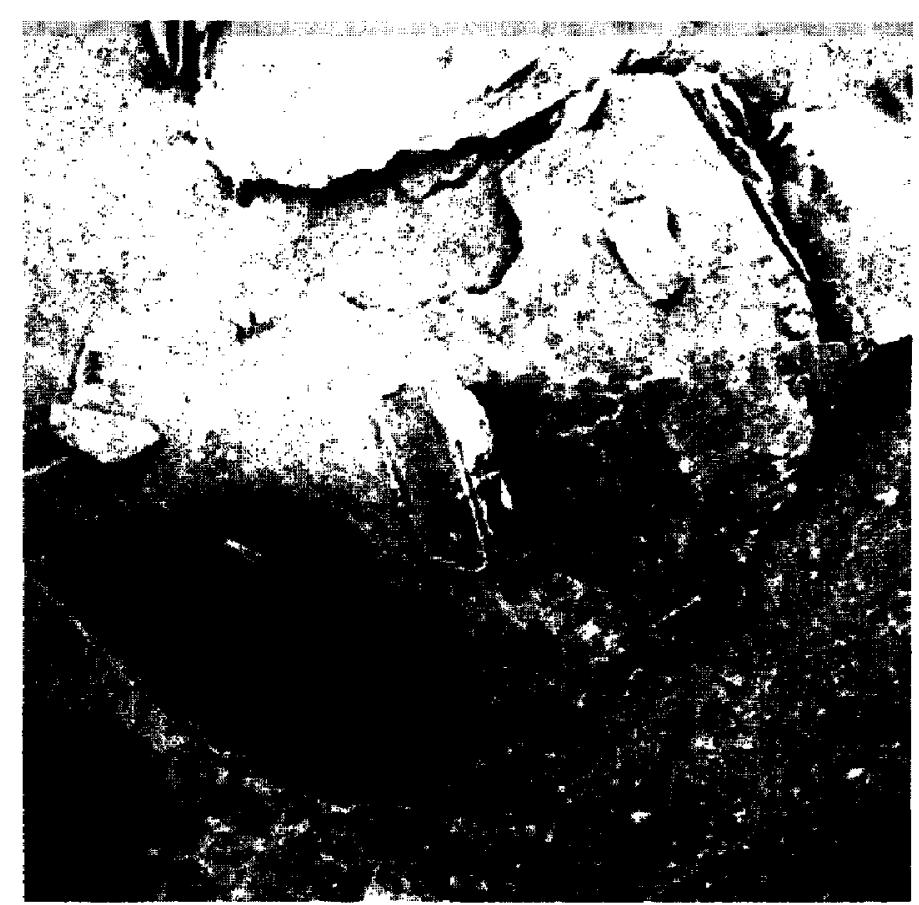

Undissolved muscovite particle $2500 x$

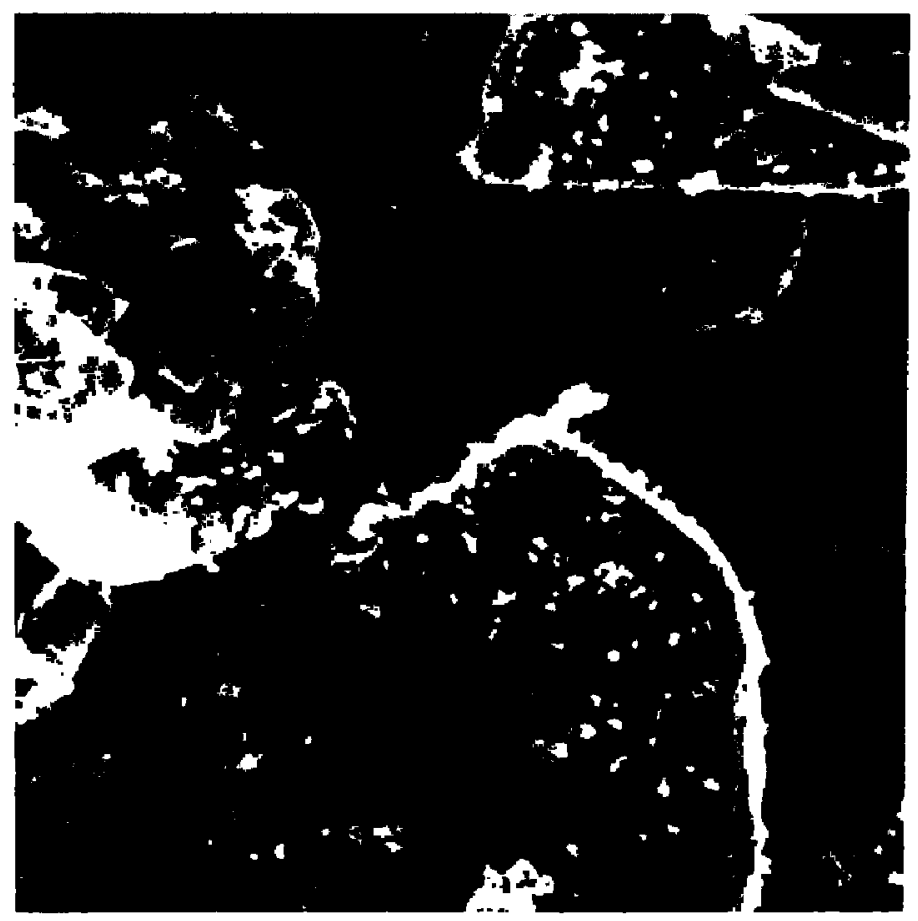

Muscovite particles dissolved $40 \% 2500 \times$

Fig. 11. Electron micrographs companng undıssolved and partıally dissolved muscovite particles. 


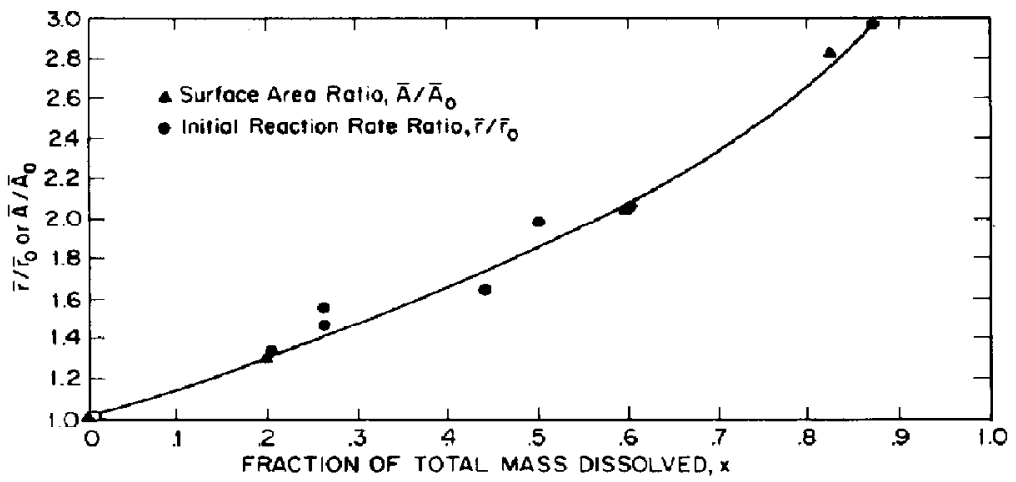

Fig. 12. Comparison of reaction rates and wetted surface areas for partially dissolved and undissolved kaolinite particles.

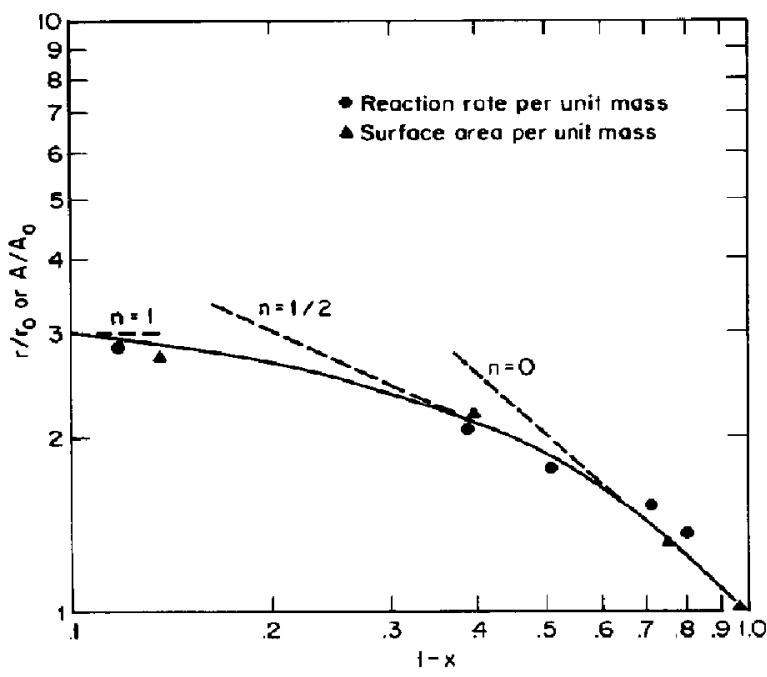

Fig. 13. Determination of solid phase reaction order as a function of fractional mass remaining after partial dissolution. previously calculated for the $20 \mu \mathrm{m}$ muscovite particles. The reactive surface area of kaolinite was taken as the area of the exposed alumina faces, or one half the total wetted surface area.

The specific rate constants per unit reactive surface area are shown as a function of the reciprocal absolute temperature in Fig. 15. The linear nature of these semilog plots indicates that the dissolution of silicates by hydrofluoric acid follows an Arrhenius temperature dependence.

$$
\ln k=\ln k_{0}-\frac{E}{R}\left(\frac{1}{T}\right)
$$

where $E$ may be defined as an apparent activation energy. By comparing the slopes of these plots it can be seen that silicates having the same octahedral sheets are characterized by similar activation energies. The activation energies of each of the aluminosilicates except sodium montmorillonite are approximately $13 \mathrm{kcal} / \mathrm{g}$ mole, while the activation energies of the mag-
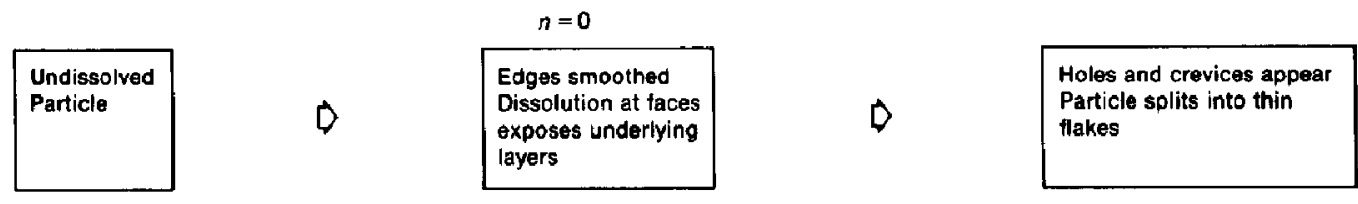

$n=1 / 2$

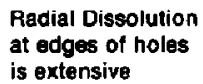

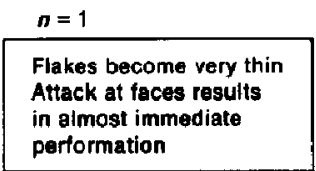

D

Fig. 14. Flow chart description of the dissolution of a kaolinite particle. 
Table 3. Structural characteristics of minerals studied

\begin{tabular}{|c|c|c|c|}
\hline & Unsubstituted & $\begin{array}{l}\text { Substitution of } \\
\text { Aluminum for Silicon } \\
\text { in Tetrahedral Sheets } \\
\text { (25) }\end{array}$ & $\begin{array}{l}\text { Substitution of } \\
\text { Magnesium for } \\
\text { Aluminum in octa- } \\
\text { hedral sheets } \\
\text { (108) }\end{array}$ \\
\hline \multirow[t]{2}{*}{ Aluminosilicates } & $\begin{array}{l}\text { Kalonite } \\
(2 \text { sheets/layer })\end{array}$ & & \\
\hline & $\begin{array}{l}\text { Pyrophyllite } \\
\text { ( } 3 \text { sheets/layer) }\end{array}$ & Muscovite & $\begin{array}{l}\text { Sodium } \\
\text { Montmorillonite }\end{array}$ \\
\hline Magnesium Silicates & $\begin{array}{l}\text { Talc } \\
\text { (3 sheets/layer) }\end{array}$ & Phlogopite & \\
\hline
\end{tabular}

Table 4. Experimental rate constants $k-r=k f(\mathbf{H F})$

\begin{tabular}{|c|c|c|c|c|c|c|}
\hline \multirow[t]{2}{*}{ Mineral } & $\begin{array}{l}\text { Wetted surface } \\
\text { Area }\left(\mathrm{m}^{2} / \mathrm{gm}\right) \\
\end{array}$ & $\begin{array}{l}\text { Calculated Re- } \\
\text { active Surface } \\
\text { Area (m } / \mathrm{gm}) \\
\end{array}$ & \multirow[t]{2}{*}{$\begin{array}{c}\text { Temperature } \\
\left({ }^{\circ} \mathrm{C}\right) \\
\end{array}$} & \multicolumn{3}{|c|}{$\begin{array}{c}\text { Rate Constant } \mathbf{k} \\
\text { mole mineral dissolved/ } \\
\mathrm{cm}^{2} / \text { sec/ HF molarity }\end{array}$} \\
\hline & & & & $\begin{array}{r}\text { Total } \\
\text { Surfac } \\
\text { Ba } \\
\end{array}$ & $\begin{array}{l}\text { Wetted } \\
\text { ce Area } \\
\text { asis. }\end{array}$ & $\begin{array}{c}\text { Reactive Sur- } \\
\text { face Area } \\
\text { Basis } \\
\end{array}$ \\
\hline \multirow[t]{4}{*}{ Kaolinite } & 16 & 8.0 & 0 & $6.6 \times$ & $10^{-13}$ & $1.3 \times 10^{-12}$ \\
\hline & & & 25 & $4.9 \times$ & $10^{-12}$ & $9.8 \times 10^{-12}$ \\
\hline & & & 37.6 & $1.3 \mathrm{x}$ & $10^{-11}$ & $2.6 \times 10^{-11}$ \\
\hline & & & 49.2 & $2.7 x$ & $10^{-11}$ & $5.4 \times 10^{-11}$ \\
\hline \multirow{2}{*}{$\begin{array}{l}\text { Sodium } \\
\text { Montmorillonite }\end{array}$} & 520 & 8.7 & 0 & $8.7 x$ & $20^{-14}$ & $5.2 \times 10^{-12}$ \\
\hline & & & 25 & $4.3 \times$ & $10^{-13}$ & $2.6 \times 10^{-11}$ \\
\hline \multirow[t]{3}{*}{ Illite } & 79 & 21.0 & 25 & $2.1 \times$ & $10^{-12}$ & $8.1 \times 10^{-12}$ \\
\hline & & & 35 & $4.3 x$ & $10^{-12}$ & $1.7 \times 10^{-12}$ \\
\hline & & & 45 & $7.7 \times$ & $10^{-12}$ & $3.0 \times 10^{-11}$ \\
\hline \multirow[t]{5}{*}{ PyrophyIlite } & 22 & 0.57 & 25 & $2.3 \times$ & $10^{-13}$ & $9.0 \times 10^{-12}$ \\
\hline & & & 37.6 & $6.2 \times$ & $10^{-13}$ & $2.4 \times 10^{-11}$ \\
\hline & & & 49.2 & $1.4 \mathrm{x}$ & $10^{-12}$ & $5.4 \times 10^{-11}$ \\
\hline & & & 60 & $3,8 \times$ & $10^{-12}$ & $1.5 \times 10^{-11}$ \\
\hline & & & 70 & $5.4 \times$ & $10^{-12}$ & $2.1 \times 10^{-10}$ \\
\hline \multirow[t]{4}{*}{ Muscovite } & 30 & 0.25 & 37.6 & $3.2 \times$ & $10^{-13}$ & $3.6 \times 10^{-11}$ \\
\hline & & & 49.2 & $7.5 \times$ & $10^{-13}$ & $8.4 \times 10^{-11}$ \\
\hline & & & 60 & $1.4 \times$ & $10^{-12}$ & $1.5 \times 10^{-10}$ \\
\hline & & & 70 & $2.4 x$ & $10^{-12}$ & $2.7 \times 10^{-10}$ \\
\hline \multirow[t]{2}{*}{ Tale } & 34 & 0.57 & 25 & $1.7 \mathrm{x}$ & $10^{-12}$ & $1.1 \times 10^{-10}$ \\
\hline & & & 60 & $1.0 \times$ & $10^{-11}$ & $6.2 \times 10^{-10}$ \\
\hline \multirow[t]{4}{*}{ Phlogopite } & 41 & 0.29 & 25 & $9.5 \times$ & $10^{-13}$ & $1.5 \times 10^{-10}$ \\
\hline & & & 37.6 & $1.6 \times$ & $10^{-12}$ & $2.4 \times 10^{-10}$ \\
\hline & & & 49.2 & $2.8 \times$ & $10^{-12}$ & $4.4 \times 10^{-10}$ \\
\hline & & & 60 & $5.3 x$ & $10^{-12}$ & $8.3 \times 10^{-10}$ \\
\hline
\end{tabular}


nesium silicates are close to $10 \mathrm{kcal} / \mathrm{g}$ mole. The fact that the rate constants for sodium montmorillonite lie between the rate constants for the other aluminosilicates and the magnesium silicates can be attributed to substitutions within the octahedral alumina sheet. About $10 \%$ of the octahedral aluminum of these montmorillonite particles was replaced by magnesium.

Figure 15 also shows that the magnitudes of the specific rate constants expressed on the basis of reactive surface area are similar for all of the aluminosilicates, as are the rate constants for the magnesium silicates. Excluding montmorillonite, the differences within each group are at most $50 \%$, as compared to orders of magnitude when the rate constants are reported on the basis of total wetted surface area (Table 3). This result provides persuasive evidence that the reaction at the octahedral sheets determines the rates at which layered silicates are dissolved.

The differences between the dissolution kinetics of the aluminosilicates and the magnesium silicates in Fig. 15 can be directly attributed to the differences in the octahedral sheets. Pyrophyllite and talc, for example, have the same three layer configuration and the same unsubstituted silica sheets. On the other hand, the rate constants are not appreciably affected by the substitution of aluminum for silicon in the tetrahedral silica sheets. The rate constants of pyrophyllite and muscovite are very similar, as are the rate constants of talc and phlogopite. Fogler, Lund and McCune [20] have shown that the three dimensional feldspar lattice, which is characterized by analogous substitution of aluminum for silicon, dissolves orders of magnitude more rapidly than the unsubstituted quartz lattice. The fact that similar increases are not observed when the silica sheets of layered silicates are substituted provides further evidence that the reaction at the octahedral sheets is rate determining. Moreover, since the dissolution of layered silicates in hydrofluoric acid is always stoichiometrically

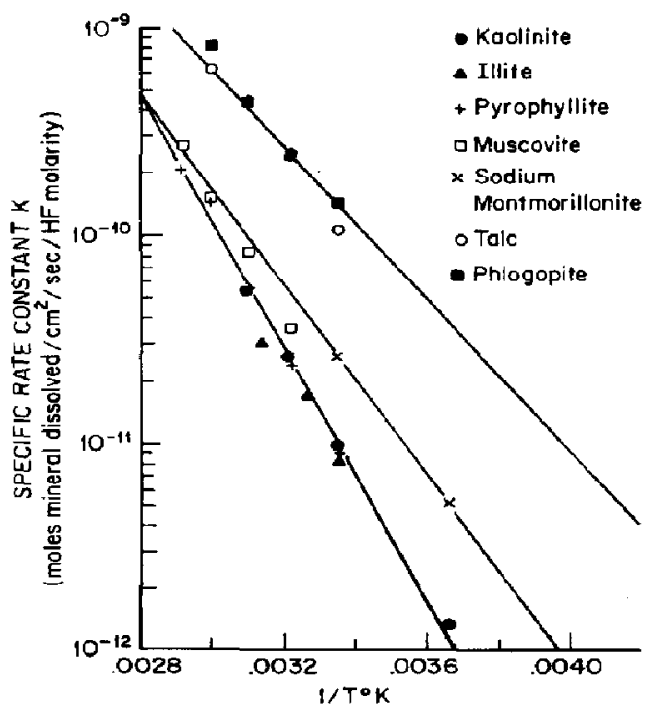

Fig. 15. Specific rate constants $k$ based on reactive surface area. uniform, it can be further concluded that the dissolution of the octahedral sheets is followed by the rapid attack of the remaining exposed portions of the corresponding silica sheets.

\section{SUMMARY}

The dissolution of layered silicate particles in hydrofluoric acid was studied by initial rate experiments and by the examination of partially dissolved particles with a scanning electron microscope. It was concluded that the three layer lattices are attacked at the unit cell edges, while the two layer kaolinite structure is dissolved at both the edges and the planar faces. A model of particle attack was developed, having the form

$$
\frac{-\bar{r}(X)}{-\bar{r}(X=0)}=(1-X)^{n-1}
$$

where $X$ is the fraction of the particle mass dissolved, $-\bar{r}_{A}(X)$ is the rate of dissolution per unit mass, and the exponent $n$ is characteristic of the nature of attack. It was determined that the dissolution of the three layer lattices can be modeled as radial attack at the edges, for which $n=1 / 2$. In contrast, the values of $n$ describing the dissolution of kaolinite vary from zero to one as the dissolution proceeds to completion.

Analysis of track etching data showed that the reaction at the edges is limited to only a small fraction of the exposed surface. Consequently, the total wetted surface area is not a valid basis for the comparison of dissolution rates. When measured rates of dissolution were expressed on the basis of estimated reactive surface areas, it was determined that layered silicates having the same octahedral sheet are characterized by similar kinetics. Comparable activation energies and rates of reaction were determined for various aluminosilicates as well as for several magnesium silicates. It was concluded that the layered silicates are attacked preferentially at sites where the octahedral alumina and magnesia sheets are exposed, and that the reaction at these sites determines the rate at which the entire lattice is dissolved.

\section{REFERENCES}

[1] Blumberg A. A., J. Phys. Chem. 1959631129.

[2] A. A. Blumberg and Stavrinou S. C., J. Phys. Chem. 196064 1438.

[3] Osthaus B., Clays and Clay Minerals. Nat. Res. Counc. Pub. 327 (1954).

[4] Osthaus B., Clays and Clay Minerals. Nat. Res, Counc. Pub. 456 (1956).

[5] Miller R. J., Soil Sci. Soc. Am. Proc. 19652936.

[6] Packter A., Chem. \& Ind. 1955431384.

[7] Turner R., Ph.D. Thesis, University of California, Davis 1964.

[8] Novak I. and Cicel B., Clays Clay Min., 197826341.

[9] Eeckman J. P. and Laudelout H., Kolloid-Z. 196117899.

[10] Grandquist W. T. and Sumner C. G., Clays and Clay Minerals. Nat. Res. Counc. Pub. 457 (1957).

[11] Gastuche M. C. and Fripiat J. J., Proc. Intern. Clay Conf., Stockholm 1963153.

[12] Hulbert J., Clays \& Clay Min. 19708337.

[13] Kline W. E., Ph.D. Thesis, University of Michigan 1980.

[14] Brooks C. S. and Purrell W. R., Trans. A.I.M.E., 1952195 289. 
[15] Seevers D. O., National Meeting of A.l.Ch.E., Pittsburgh 1964.

[16] Korringa J., Seevers D. O. and Torrey H. C., Phys. Rev. $1962127 \mathrm{I143}$.

[17] Halen E. L., Phys. Rev. 195080580.
[18] Bean C. P., Doyle M. V. and Entine G., J. Appl. Phys. 1970 411454.

[19] Anderson J. A., Personal communication 1979.

[20] Fogler H. S., Lund K. and McCune C. C., Chem. Engng Sci. 1975301325 . 